Check for updates

Portsmouth Hospitals NHS Trust

drparthakar@gmail.com Follow Partha on Twitter: @parthaskar Cite this as: BMJ 2021;374:n2080 http://dx.doi.org/10.1136/bmj.n2080 Published: 31 August 2021

\section{THE BOTTOM LINE}

\section{Partha Kar: Jealousy, rivalry, and disdain-the toxicity of specialty stereotyping}

\section{Partha Kar consultant in diabetes and endocrinology}

It's all around you, especially if you venture into the world of social media: GPs against hospital specialists, hospital specialists against GPs, and specialists against one another. Everyone is eager to score points, having underlying angst about what others are doing, feeling hard done by and mistreated, or thinking that colleagues deserve more respect. And when a comment cuts too close to the bone, one person's bit of old school stereotyping becomes another person's disrespectful insult.

Some seem to believe that this simply reflects the tough times we live in-perhaps the frustration of reduced resources or a huge patient backlog, combined with the aftermath of dealing with the pandemic and future uncertainties. Indeed, there is that element to it. Yet to simply put it down to the pressures people are under ignores decades of history regarding "banter" between specialties, in hospital corridors and medical social circles. The stereotypes of different specialties are never too far from medics' general consciousness. You hear them from seniors as you develop in your training. And it would be blatant hypocrisy if we, as a profession, failed to recognise that you become part of that history when you perpetuate those stereotypes to your trainees.

All that we're seeing now is that what previously happened in the private social circles of medics is now happening in the open, on social media. And with that, all of the scars of interprofessional jealousy, rivalry, and disdain are laid bare to the general public.

As clinicians we have our own choices to make, and we have to bear the consequences. We could calm the rhetoric-and the specialty stereotyping-and have a workforce with a degree of mutual respect, irrespective of the specialty people work in. Or we could accept that this discourse is simply part of the culture we've created and accept the toxicity that comes with it (after all, it's not new-it's simply more public). But if you decide that this is simply part of medicine's culture, and you then decide to have a go at another specialty with some sarcastic comment, you need to be ready to take it on the chin when the other party fires back with gusto.

I've worked for many years as a consultant in diabetes and have heard more than enough barbs against the specialty, some as "banter" and some with added spikes: "The lazy specialty," "Glorified GP," "Just go and do some general medicine," or "Why does diabetes need a consultant anyway?” Those comments used to sting. With time you learn to ignore some, answer some with humour, and try to stay away from a retort. With time, they've all quietened down. Personally, my approach has been to stay away from any judgmental comments about other specialties, which has reaped dividends on a personal basis.

For what it's worth, try doing your own small bit too. It's important that we all recognise that this bad feeling between specialties is a problem we need to reflect on. If you ease off the mockery, the barbed comments, or the clever slights against other specialties designed to gain kudos among your followers, then maybe, just maybe, you will have contributed to breaking the incessant cycle of in-fighting.

Competing interests: www.bmj.com/about-bmj/freelance-contributors.

Provenance and peer review: Commissioned; not externally peer reviewed. 